\title{
EXPRESSÃO MILITAR DO SETOR ESTRATÉGICO ES PACIAL: EVOLUÇÃO E O DIREITO. CASO BRASILEIRO: QUARTA GERAÇÃO DA FORÇA AÉREA BRASILEIRA
}

\author{
José VAgNer VitaL* \\ Maria Helena Fonseca de Souza Rolim**
}

\begin{abstract}
Sumário: 1. Preliminares. 2. Uso Militar do Espaço Exterior e o Direito Internacional. 3. Do Poder Militar Espacial. 4. Doutrina para Domínio Espacial de Combate. 5. Ameaças a Sistemas Espaciais. 6. O PESE e a Quarta Geração da Força Aérea Brasileira. 7. Considerações Finais.
\end{abstract}

RESUMO: A evolução e transformações das tecnologias aplicadas aos usos do espaço exterior interconectadas com o uso militar do espaço exterior a evidenciam a pressão dos fatos sobre o direito, avocando reflexão sobre o corpus juris internacional sobre a questão, em nível de soft law e hard law. Mesmo no contexto de autodefesa, as atividades espaciais militares possuem aspectos ofensivos e defensivos que precisam ser considerados e podem ser executadas ao abrigo da Carta das Nações Unidas (considerando o direito à autodefesa) e do Tratado do Espaço (ao se entender o termo “propósito pacífico" equivalente ao termo "não agressão”, exceto para autodefesa), além de outros tratados que podem ser evocados em situações de conflito, no âmbito

\footnotetext{
* Brigadeiro do Ar, Força Aérea Brasileira, Comissão de Coordenação e Implantação de Sistemas Espaciais (CCISE); Vice-Presidente. Diploma em Engenharia Eletrônica pelo Instituto Tecnológico de Aeronáutica (ITA); Master of Science in Microwave Egineering pela Technische Universitaet Muenchen (TUM); Curso da Escola de Comando e Estado-Maior da Aeronáutica (ECEMAR); Curso de Política, Estratégia e Alta Administração do Exército Brasileiro (CPEAEX); Foi fundador da CCISE; Elaborou o texto base para o Programa Estratégico de Sistemas Espaciais (PESE) e coordenou as equipes de revisão e elaboração dos anexos técnicos do PESE.
}

The thoughts and opinions expressed are those of the author and not necessarily of the Brazilian government, the Ministry of Defense, the Brazilian Air Force.

** Doutora em Direito Internacional pela Universidade de São Paulo; Consultora ONU há 35 anos; Professora Visitante do UN/IMLI/Malta; Foi Professora de Direito Internacional da Faculdade de Direito da Universidade de São Paulo; Foi Professora de Direito Espacial do Instituto Tecnológico de Aeronáutica; Foi consultora jurídica do Instituto Nacional de Pesquisas Espaciais para o Programa Brasileiro para a Estação Espacial Internacional e para o Programa Sino-Brasileiro de Satélites Ambientais; Membro da International Astronautical Federation. 
do Direito Internacional Humanitário. Este artigo consubstancia o caso brasileiro, onde a Força Aérea Brasileira apresenta o entendimento do Brasil quanto ao Tratado do Espaço e à Carta das Nações Unidas, estruturando sua aplicação militar do espaço exterior de acordo com os documentos políticos e doutrinários do Ministério da Defesa do Brasil, sabidamente, a Política de Defesa Nacional, a Estratégia Nacional de Defesa e o Programa Estratégico de Sistemas Espaciais. As operações militares descritas neste artigo revelam que situações fáticas emergentes carecem de tutela jurídica com elevado grau de efetividade.

Palavras-Chave: Direito Internacional; Espaço; Força Aérea Brasileira; Carta das Nações Unidas; Tratado do Espaço; Doutrina para Domínio Espacial de Combate; PESE.

AbstraCt: The evolution and transformation of space technology interconnected with the military use of outer space highlights the pressure of the facts on the law, calling for reflection on the international corpus juris on the issue, at the level of soft law and hard law. Even in the context of self-defense, military space activities have offensive and defensive aspects that need to be considered and can be carried out under the United Nations Charter (considering the right to self-defense) and the Space Treaty (when understanding the term "peaceful purpose" equivalent to the term "non-aggression", except for self-defense), in addition to other treaties that can be evoked in conflict situations, adopted by the International Humanitarian Law. This article sought to bring the Brazilian case, where the Brazilian Air Force translated Brazil's understanding of the Space Treaty and the United Nations Charter, structuring its military application of outer space according to the political and doctrinal documents from the Brazilian Ministry of Defense, known as the National Defense Policy, the National Defense Strategy and the Strategic Space Systems Program. The military operations described in this article reveal that emerging factual situations lack legal protection with a high degree of effectiveness.

KEYwords: International Law; Space; Brazilian Air Force; United Nations Charter; Space Treaty; Combat Space Domain Doctrine; PESE. 


\section{Preliminares}

\section{Ex facto jus oritur}

As ideias e conceitos elencados ao longo do trabalho respeitam as convenções e tratados internacionais dos quais o Brasil é signatário, em particular no âmbito do Direito Espacial. A questão da militarização do espaço exterior, com ênfase para a aplicação de meios espaciais nas operações espaciais militares de Defesa, evidencia a pressão dos fatos sobre o direito avocando reflexão sobre o corpus juris internacional sobre a questão, em nível de soft law e hard law. ${ }^{1}$ As operações militares descritas neste artigo revelam que situações fáticas emergentes carecem de tutela jurídica com elevado grau de efetividade.

Para afastar interpretações equivocadas, cabe aqui enfatizar que os paradigmas adotados neste trabalho não violam o Artigo IV do Tratado sobre Princípios Reguladores das Atividades dos Estados na Exploração e Uso do Espaço Cósmico, inclusive a Lua e Demais Corpos Celestes de 1967(Tratado do Espaço) $)^{2}$ :

"Os Estados-Partes no Tratado se comprometem a não colocar em órbita ao redor da Terra quaisquer objetos que portem armas nucleares ou qualquer outro tipo de armas de destruição em massa, nem instalar tais armas em corpos celestes, nem estacionar tais armas no espaço exterior de qualquer outra maneira. A lua e outros corpos celestes serão usados por todos os Estados Partes no Tratado exclusivamente para fins pacíficos. É proibida a instalação de bases, instalações e fortificações militares, o teste de qualquer tipo de arma e a realização de manobras militares em corpos celestes. Não é proibido o uso de pessoal militar para pesquisas científicas ou quaisquer outros fins pacíficos. O uso de qualquer equipamento ou instalação necessário para a exploração pacífica da lua e outros corpos celestes também não deve ser proibido."

1 Em Direito, o termo soft law refere-se a resoluções, códigos de conduta (embora por vezes o código adota alguns artigos que já são hard law, isto é já foram adotadas por tratados ou costume), enquanto o termo hard law remete a normas vigentes e cogentes.

2 Tratado do Espaço, encontrado em http://www.planalto.gov.br/ccivil_03/decreto/1950-1969/ D64362.html. 
Os conceitos doutrinários a serem apresentados se referem a atividades que não estão relacionadas a armas nucleares e nem a armas de destruição em massa. Tão pouco há menção de instalações militares fora do planeta Terra, o que evidencia que não há violação do Artigo IV do Tratado do Espaço. Oportuno mencionar que as atividades militares para autodefesa são consideradas lícitas por diversas nações e perfeitamente compatíveis com os conceitos de exploração e uso pacífico do espaço exterior. ${ }^{3}$

Exemplo é a possibilidade de atividade militar no espaço exterior para segurança e autodefesa ser considerada lícita e ter sido incluída no European Union Draft Code of Conduct for Outer Space Activities. ${ }^{4}$ Em face do propósito, do escopo e dos princípios gerais deste Código de Conduta, pretendido pelos europeus, encontramos aspectos relacionados à segurança (tanto quanto a defesa contra a ameaças quanto a mitigação de riscos) e sustentabilidade, além de enfatizar a aplicabilidade a todas as atividades espaciais, governamentais, não-governamentais, civis e militares. Neste contexto, o draft proposto para Código de Conduta não refuta a existência de atividades militares no espaço exterior. $\mathrm{Na}$ realidade, os princípios basilares deste instrumento jurídico adotam teleologia compatível com as normas do Direito Espacial, inter alia, uso pacífico do espaço exterior; liberdade no espaço Exterior (Tratado do Espaço); direito à autodefesa (Carta das Nações Unidas $^{5}$ ); ações não prejudiciais (cabe aqui ressalvar os casos de autodefesa).

3 Professor Dale Stephens afirma sobre o termo "peaceful" adotado no Tratado do Espaço: "[...] both the USSR and the United States engaged in military activities in space, with the deployment of military surveillance satellites and the conduct of military testing. Indeed, because of this State practice, it came to be understood that "peaceful" meant "non-aggressive." Dale Stephens, The International Legal Implications of Military Space Operations: Examining the Interplay between International Humanitarian Law and the Outer Space Legal Regime, Stockton Center for the Study of International Law, 2018, Volume 94, 94 INT’L L. STUD. 75, ISSN 2375-2831,81.

4 Ver Projeto de Código de Conduta para o Espaço Exterior da União Europeia, Subcomitê Científico e Técnico, quadragésima oitava sessão do COPUOS de 7 a 18 de fevereiro de 2011, palestra proferida por J. Mayence "Um Código de Conduta para o Espaço Exterior."

O Código de Conduta para as atividades espaciais na Europa pretende ser a continuação das Medidas de Transparência e de Fortalecimento da Confiança (TCBM em Inglês) e um complemento ao Tratado do Espaço Exterior das Nações Unidas e suas diretrizes. (https://www.unoosa.org/oosa/en/ ourwork/copuos/stsc/2011/eu-draft-code-of-conduct.html).

5 Carta das Nações Unidas, Art. 51: "Nada na presente Carta deve prejudicar o direito inerente à legítima defesa individual ou coletiva se um ataque armado ocorrer contra um Membro das Nações Unidas, até que o Conselho de Segurança tenha tomado as medidas necessárias para manter a paz e a 
Outra evidência factual da natural aplicação de recursos militares e armamentos não nucleares ou de destruição em massa no espaço exterior, é o crescente número de países que estão criando ou organizando seus Comandos Militares Espaciais, ${ }^{6}$ como por exemplo a França, o Japão, os Estados Unidos e a Itália. Desta forma, os fundamentos acima apresentados e os fatos mencionados evidenciam que o alinhamento dos conceitos doutrinários apresentados como alternativa para a Força Aérea Brasileira com os fatos atuais encontra respaldo no ordenamento jurídico internacional vigente e na prática internacional.

Considerando que o Direito Espacial é informado pelo princípio da aplicação da extraterrestrialidade da lei, é imperioso que o movimento de lege ferenda para de lega lata na elaboração do ordenamento jurídico internacional a ser aplicado às atividades militares no espaço exterior seja eivado de elevado grau de efetividade para regulamentar adequadamente a presença militar no espaço exterior necessária no domínio de combate e à defesa nacional.

\section{Uso Militar do Espaço Exterior e o Direito Internacional}

Desde a remota antiguidade o espaço exterior fora contemplado pelos astrônomos. Povos civilizados, na antiguidade histórica, descrevem com adequada precisão o movimento aparente dos astros nos céus ${ }^{7}$, embora o desvendar dos mistérios da exploração do espaço exterior seja atividade que

segurança internacionais. As medidas tomadas pelos Membros no exercício deste direito de legítima defesa devem ser imediatamente comunicadas ao Conselho de Segurança e não devem, de forma alguma, afetar a autoridade e responsabilidade do Conselho de Segurança sob a presente Carta de tomar, a qualquer momento, ações como esta considera necessário para manter ou restaurar a paz e a segurança internacionais."

6 Ver Defense Space Strategy Summary. Disponível em:

https://media.defense.gov/2020/Jun/17/2002317391/-1/-1/1/2020_DEFENSE_SPACE_STRATEGY_SUMMARY.PDFhttps://media.defense.gov/2020/Jun/17/200231739 $1 /-1 /-1 / \overline{1} / 2020$ DEFENSE_SPACE_STRATEGY_SUMMARY.PDF .

Ver também RTP Notícias. Japão cria força espacial para combater eventuais ameaças, disponível em: https://www.rtp.pt/noticias/mundo/japao-cria-forca-espacial-para-combater-eventuais-ameacas_ n1 199283

7 Aydano Barreto Carleial, Uma Breve História da Conquista Espacial in Parcerias Estratégicas, Centro de Estudos Estratégicos do Ministério da Ciência e Tecnologia/Agência Espacial Brasileira, Brasília, Brasil, 1999, 21. 
se inicia na Idade Moderna. A Era espacial surge no século XX com o lançamento e colocação em órbita do primeiro satélite artificial, em 1957, quando a ex-União das Repúblicas Socialistas Soviéticas (ex-URSS) lança com sucesso ao espaço exterior o Sputinik I. ${ }^{8}$

$\mathrm{O}$ rápido processo de desenvolvimento da ciência espacial, após evento, e imediatamente seguido pelos americanos, evidenciou que a busca pelo domínio das tecnologias para a colocação em órbita de naves tripuladas ou não suplantava a discussão sobre a eventual ilegalidade do sobrevoo destes artefatos espaciais. A este fato somaram-se, por um lado, a polarização política global da época nas atividades desenvolvidas pela ex-URSS e pelos Estados Unidos da América (EUA), e, por outro lado, a impossibilidade de reação das outras nações. Quanto ao cenário político, deve-se lembrar que estava caracterizado pelo auge da Guerra Fria, colocando as nações na posição de partes interessadas no sucesso de uma ou outra das nações líderes das atividades espaciais.

Neste contexto, a questão vinculou-se, em sua gênese, a três fatores preponderantes: a) não questionamento dos aspectos legais da fronteira que se abria para a Humanidade: a possibilidade de livre circulação no espaço exterior e consequentes usos; b) grande expectativa quanto ao impacto direto no delicado balanço do poderio militar dos dois blocos hegemônicos das novas técnicas espaciais; e c) reconhecimento tácito de que nenhuma outra nação seria capaz de atuar e reagir no mesmo patamar na arena espacial por falta de recursos tecnológicos avançados.

A ausência de protesto por parte dos Estados, atuantes em atividades espaciais ou não, em relação à exploração e utilização do espaço exterior, evidenciou um consentimento tácito da comunidade internacional vis-à-vis a estas novas situações fáticas. Por um lado, ocorreu um comportamento atuante e positivo dos Estados espaciais e, por outro lado, uma conduta tolerante, uma abstenção por parte dos não espaciais, que não se manifestaram ou se opuseram às atividades espaciais emergentes. Para Imbiriba, 'este reconhecimento tácito configurou um certo tipo de consensus lato

8 Sobre Uso Militar do Espaço Exterior ver Bin Cheng, Studies in International Space Law, Clarendon Press Oxford, 1977, 513-38; Francis Lyall and Paul b. Larsen, Space Law : A Treatise, Asgate Publishing, 2011,499-532. 
sensu que se deveu, em parte, à finalidade pacífica, exploratória e científica com que aquelas atividades foram encaradas. Este consenso tácito, configurou uma forma imperfeita, talvez, de Costume, não bem cristalizado, mas que influenciaria sobremaneira a síntese normativa a respeito, elaborada a partir das Nações Unidas. ${ }^{9}$

Momento histórico em que as Nações Unidas, por intermédio do Comitê para Usos Pacíficos do Espaço Exterior (COPUOS) desempenharam papel fundamental nas origens do Direito Espacial, adotando os pilares desta nova Era: liberdade das atividades espaciais; não possibilidade de avocar soberania sobre o espaço exterior e usos pacificos do espaço exterior. Oportuno observar que o termo Humanidade, neste cenário internacional, ultrapassa pela primeira vez os foros literários, sendo objeto de debates jurídicos no âmbito do COPUOS e, finalmente, integrado ao mundo jurídico, quando de sua inserção em resoluções, convenções e tratados internacionais no plano do Direito Espacial.

Tecnologia, expansão, dominação e vertente militar estão na gênese do Direito Espacial a reger crescente usos militares do espaço exterior. ${ }^{10} \mathrm{E}$ aqui emerge reflexão sobre a interação e interpretação holística entre o Direito Internacional Humanitário ${ }^{11}$ e o corpus juris do Direito Espacial. ${ }^{12}$ Oportuno observar que somente faremos breve interpretação do Tratado do Espaço, ratificado pelo Brasil.

9 Ver Maria de Nazaré Oliveira Imbiriba, Do Princípio do Patrimônio da Humanidade, FADUSP, SP, 1980, 19.

10 "The militarization of space includes the continued deployment of military or dual use satellites that assist military forces in the terrestrial environment. For example, the Space Security Index (SSI) notes that as of 2016 the United Sates has 150 dedicated military satellites, in addition to 31 GPS satellites, Russia has 54 dedicated military space satellites in addition to 31 GPS satellites, and China has 58 dedicated military satellites.(Jessica West ed. 2017) 93-94. The United States, China and Russia also have developed ground-based anti-satellite (ASAT) missile capability. These States are also developing space-based kinetic kill vehicles, radio frequency weapons, space "mines", microsatellites capable of rendezvous and proximity operations, and "dazzling" lasers that can be used to degrade satellite functionality. Id. At 114-16." Apud Dale Stephens, supra nota 3, 76.

\section{Idem, 77.}

12 Tratado do Espaço, 1967, supra nota 2; Acordo sobre o Salvamento de Astronautas e Restituição de Astronautas e de Objetos Lançados ao Espaço Cósmico, 1968; Convenção sobre Responsabilidade Internacional por Danos Causados por Objetos Espaciais,1972; Convenção Relativa ao Registro de Objetos Lançados no Espaço,1974. Direito Espacial, Coletânea de Documentos, Convenções, atos internacionais e diversas disposições legais em vigor, Agência Espacial Brasileira e Sociedade Brasileira de Direito Aeroespacial, RJ, 2003, 1-20. 
A teleologia do Tratado do Espaço, definida em seu Preâmbulo, tem como fonte imediata a Resolução 1962 (XVIII) da Assembleia Geral das Nações Unidas (AGNU), de 13 de dezembro de 1963, transformando em direito positivo convencional os ideários cristalizados nesta resolução: o interesse que apresenta para toda a Humanidade o progresso da exploração e uso do espaço exterior para fins pacíficos. O binômio interesse da Humanidade e fins pacíficos rege, a partir de então, as atividades dos Estados em relação à utilização e exploração do espaço exterior.

Para a garantia da irradiação destes princípios ao espaço exterior o Tratado do Espaço, em seu Artigo III, consubstancia a aplicação extraterrestrial do direito internacional, inclusive da Carta das Nações Unidas, às atividades espaciais, com a finalidade de manter a paz e a segurança internacional e de favorecer a cooperação internacional. O campo de aplicação do Tratado é tutelar as atividades dos Estados no espaço exterior, inclusive a Lua e demais corpos celestes. É possível observar que as anteriores Resoluções da AGNU mencionam "espaço cósmico" e "corpos celestes". Entretanto, pela terminologia adotada, o Tratado inclui a concepção de "corpos celestes" na noção e "espaço cósmico", questão que suscita crítica da doutrina. ${ }^{13}$

De fundamental interesse, o Artigo IV do Tratado do Espaço incorpora princípios essenciais do Direito Espacial vinculado à limitação de armamentos no espaço exterior, reiterando usos exclusivamente para fins pacíficos, ${ }^{14}$ embora não defina o termo, e tipificando a proibição de colocar em órbita qualquer objeto portador de armas nucleares ou de qualquer outro tipo de armas de destruição em massa; proibição nos corpos celestes o

13 Bin Cheng apresenta críticas ao termo "inclusive a Lua": It has lost the use of a term with an accepted meaning describing the space beyond terrestrial national space and the myriad celestial bodies. Consequently, whenever references has to be made in this area, some long winded specification will now be required. The treaty specifies on practically every occasion, that the term includes the moon and other celestial bodies. This pleonasm is further aggravated by singling on the moon for special mention in most instances." Supra nota 8, 226.

14 Para Verschoor "The principle of peaceful use of outer space laid down in the Space Treaty correlates with one of the leading principles of general international law - the principle of disarmament. At the present stage the primacy of peaceful use of outer space does not imply a complete ban on all military activity in outer space, but it does impose an obligation on State while strictly observing the existing norms in this sphere of military activities by using for this purpose general an partial measures for disarmament and reduction of armaments.", Diederiks- Verschoors, An Introduction to Space Law, Kluwer Law and Taxation Publishers, The Netherlands, 1993, 25. 
estabelecimento de bases, instalações ou fortificações militares, os ensaios de armas de qualquer tipo e a execução de manobras militares. Entretanto, não proíbe a utilização de pessoal militar para fins de pesquisas científicas ou para qualquer outro fim pacífico, no sentido de não agressivo. Para a doutrina, este dispositivo legal não bane os usos militares do espaço exterior, mas restringe somente alguns aspectos das atividades militares. 15 Posição inevitável, considerando-se que as tecnologias operacionais de base foram e ainda são, em determinados níveis, o desdobramento de pesquisas militares.

Em síntese, a interpretação conjugada entre os Artigos III e IV do Tratado do Espaço revela que atividades militares desenvolvidas de modo consistente com a Carta das Nações Unidas é permitida nos limites das restrições impostas pelo Direito Internacional, genericamente considerado, e especificamente à luz do Direito Espacial.

Considerando o Manual de Leis de Guerra do Departamento de Defesa dos Estados Unidos da América (Manual de Guerra - EUA), ${ }^{16}$ atualizado para lidar com o Tratado do Espaço em tempos de paz ou de guerra, verifica-se que o documento interpreta de maneira mais profunda o termo “propósitos pacíficos”, contido no referido Tratado, ao equipará-lo ao termo "não agressivo", mantendo consistência com a Carta das Nações Unidas. Os conceitos doutrinários propostos à Força Aérea Brasileira seguem esta interpretação ao tratar das aplicações espaciais militares. Este posicionamento é significativo, pois redireciona as opiniões iniciais defendidas por alguns Estados e acadêmicos de que toda atividade militar era proibida no espaço exterior.

15 Lyall and Larsen afirmam "Article IV does not ban the military from outer space but to a degree it restricts military activities. There is a 'common interest of all mankind in the progress of the exploration and use of space for peaceful purposes', but how does that interest interact with military concerns? 'Military use' has a variety of aspects: the employment of military personnel and equipment; the passive or non-aggressive use of space; the use of civilian space system for military purpose; the use of weapons in space; the incursion into space of military weapons; the interference with space located equipment from space; the interference with space located from Earth." Supra nota 8, 515-17.

16 "Law of War Manual, supra note 3, \$14.10.4, at 943-45". Apud Dale Stephens, The International Legal Implications of Military Space Operations: Examining the Interplay between International Humanitarian Law and the Outer Space Legal Regime, supra nota 5. 


\section{Do Poder Militar Espacial}

No caso brasileiro, a Estratégia Nacional de Defesa (END) ${ }^{17}$ e o Manual de Doutrina do Ministério da Defesa (MDS51-M-04) ${ }^{18}$ reconhecem o Comando da Aeronáutica como o responsável natural pelo emprego militar no Domínio Aeroespacial. A END já traz frases que reputam o emprego do espaço exterior em atividades de Defesa:

"Os setores espacial e cibernético permitirão, em conjunto, que a capacidade de visualizar o próprio país não dependa de tecnologia estrangeira e que as três Forças, em conjunto, possam atuar em rede, instruidas por monitoramento que se faça também a partir do espaço." (Estratégia Nacional de Defesa - END)

Neste contexto, para entendermos como os aspectos militares estão organizados para as aplicações espaciais, pode-se chegar ao entendimento do conceito de Poder Militar Espacial, na perspectiva brasileira, partindo-se da definição oficial de Poder Aeroespacial, ${ }^{19}$ conforme o MDS51-M-04. Nesta linha, considerando-se que o Poder Espacial (civil e militar) é parte integrante do Poder Aeroespacial, pode-se afirmar que o Poder Espacial resulta da integração dos recursos que a Nação dispõe para a utilização do espaço exterior, quer como instrumento de ação política e militar, quer como fator de desenvolvimento econômico e social, visando a conquistar e a manter os objetivos nacionais.

Assim como o Poder Espacial integra o Poder Aeroespacial, da mesma forma, o Poder Militar Espacial é parte integrante do Poder Militar Aeroespacial. Seguindo o mesmo raciocínio anterior e partindo-se da definição de Poder Militar Aeroespacial, conforme o Manual de Doutrina do Ministério da Defesa (MDS51-M-04), pode-se inferir a seguinte definição considerando o pensamento militar brasileiro:

17 BRASIL. Estratégia Nacional de Defesa (END). Ministério da Defesa (MD). Brasília-DF, 2012

18 Manual de Doutrina do Ministério da Defesa (MDS51-M-04). https://www.gov.br/defesa/ pt-br/arquivos/File/legislacao/emcfa/publicacoes/md51a_ma_04a_doutrinaa_militara_dea_ defesaa_2aa_ed2007.pdf.

19 PODER AEROESPACIAL: é a projeção do Poder Nacional resultante da integração dos recursos de que a Nação dispõe para a utilização do espaço aéreo e do espaço exterior, quer como instrumento de ação política e militar, quer como fator de desenvolvimento econômico e social, visando conquistar e manter os objetivos nacionais. (Manual de Doutrina do Ministério da Defesa MDS51-M-04). 
O Poder Militar Espacial é a parte integrante do Poder Espacial que compreende a Força Aérea, suas bases e suas estruturas de C2 (Comando e Controle), logisticas e administrativas, bem como os meios adjudicados pelos poderes naval e militar terrestre e outros meios, quando vinculados ao cumprimento da missão do Poder Militar Espacial e submetidos a algum tipo de orientação, comando ou controle de autoridade militar espacial.

Consta no MDS51-M-04, que os componentes da Expressão Militar do Poder Nacional são o Poder Naval, o Poder Militar Terrestre e o Poder Militar Aeroespacial. Por analogia às definições de Poder Naval e de Poder Militar Terrestre, pode-se inferir que o Poder Militar Espacial é, pelo menos, a parte integrante do Poder Aeroespacial capacitada a atuar militarmente no espaço exterior. ${ }^{20}$

Essa visão mais ampla de Poder Espacial traz à tona dois aspectos importantes que precisam ser considerados, além dos historicamente conhecidos de pesquisa e desenvolvimento e inovação, quais sejam: a) a necessidade de militarização do espaço exterior, respeitando os tratados internacionais assinados para o uso pacífico do espaço e mantendo a presença militar necessária neste Domínio de Combate para a Defesa Nacional; e b) a importância da participação crescente do setor privado nas atividades e investimentos espaciais, aumentando as atividades econômicas relacionadas ao setor espacial.

O termo "Poder Espacial", mencionado em 1964 por Knorr e ampliado por Lupton, revela que o Poder Espacial constitui um elemento do Poder Nacional semelhante aos Poderes Aéreo, Marítimo e Terrestre. ${ }^{21}$ Este conceito persiste ainda hoje, chegando a justificar, no caso específico desse país, a existência da Força Espacial dos Estados Unidos da América (USSF).

20 Não se restringe a apenas possuir satélites e tecnologias de acesso ao espaço, mas, também, por todos os meios que um país, ou um conjunto de países, podem obter soberanamente através do espaço, permitindo a condução de atividades espaciais necessárias para a segurança nacional e para o bem estar social de maneira ampla, incluindo: Comando e Controle; Comunicações; Navegação; Monitoramento ambiental; Sensoriamento remoto; Alarme; Vigilância; Inteligência; Cibernética; e Defesa Espacial. A bem da clareza, cabe aqui salientar, que o termo "cibernética" acima não se refere ao Setor Estratégico Cibernético propriamente dito, mas aos sistemas e tecnologias utilizados na FAB.

21 José Vagner Vital, O apoio do Programa Estratégico de Sistemas Espaciais (PESE) ao Sistema Operacional Militar Terrestre. 2016. Trabalho de Conclusão de Curso (Curso de Política, Estratégia e Altos Estudos do Exército) - Escola Comando e Estado Maior do Exército (ECEME), Rio de Janeiro, 2016, 1-33. 
Em nível comparado de sistemas militares, pode-se considerar o Poder Espacial, sob a perspectiva norte-americana, como sendo a força que uma nação possui para atingir seus objetivos, resultante das capacidades que possui para conduzir e influenciar atividades no espaço, através ou a partir dele ${ }^{24}$. Ou de maneira mais abrangente, sob a perspectiva britânica, como sendo a capacidade de uma nação projetar poder a partir do espaço, para influenciar o curso dos eventos ou o comportamento de pessoas. Levando-se em conta os aspectos acima apresentados pode-se considerar que o Poder Espacial de uma nação permite a consecução de objetivos nacionais através do uso de capacidades espaciais. ${ }^{22}$

Sob a perspectiva militar, o Poder Espacial tem características adicionais em relação ao Poder Aéreo, como: cobertura global; acesso livre a toda a superfície da Terra; sobrevoo de todos os países; grande alcance das armas no espaço exterior; tempo indefinido de voo com baixo custo operacional; e características similares a territórios no tocante às órbitas mais cobiçadas. ${ }^{23}$

A aplicação economicamente viável e exequível do Poder Espacial deve levar em consideração estas características mencionadas acima, e precisa ser planejada de forma a proporcionar uma atuação integrada e conjunta nos combates envolvendo os 5 domínios (Naval, Terrestre, Aéreo, Espacial e Cibernético). Logo, é necessário que haja uma Doutrina Espacial pragmática de operação, que considere as peculiaridades e as vantagens auferidas pelas operações baseadas no espaço exterior. ${ }^{24}$

22 O General John E. Hyten, Comandante do Comando Espacial da Força Aérea Norte Americana (AFSC) de 2014 a 2016 afirma: "When you look at what we do in space, it's truly the most joint element of our military... Everything we do is critical to the operations of (all services) - it's critical to our economy and to the world - it's basically embedded in everything we do." Tradução livre do autor: "Quando você olha para o que fazemos no espaço, é realmente o elemento mais conjunto das nossas Forças militares... Tudo o que fazemos é fundamental para as operações (de todas as Forças ) - é fundamental para a nossa economia e para o mundo - está basicamente inserido em tudo o que fazemos."

23 HAMBY, James R.; SMITH JR, Odell A..US Space Command - Does it Support National Military Space Requirements? Trabalho de Conclusão de Curso do Air Command and Staff College - Air University, Maxell AFB, AL, 1987.

24 O General David Goldfein, 21st Chief of Staff of the Air Force em 2018 afirma: "Multi-domain operations is really about thinking through how we penetrate, where we need to penetrate; how we protect what we need to protect inside a contested space; how we persist in that environment for the period of time that we have to remain there, ... Our nation knows how to do that, but that muscle has atrophied a bit. That's why you hear a lot of us talking about this attribute of speed. It's not only speed in executing warfare. It's speed in how were preparing for warfare. It's speed in how we acquire. It's speed in changing our 
Para entender a importância do Poder Espacial nos teatros de operações atuais, podem-se considerar conceitos doutrinários da Escola do Controle, de acordo com David Lupton. ${ }^{25}$ Esta escola olha para o Espaço via uma analogia com o Poder Aéreo e com o Poder Naval. O controle do espaço, a exemplo do controle dos demais domínios, é vital para a dissuasão, além de ser de grande importância para vencer guerras.

O espaço precisa ser protegido para permitir o controle dos domínios permeados por ele. Este controle pode ocorrer em diversos graus, mesmo que não seja possível se obter a supremacia espacial, é preciso se obter um nível adequado de resiliência nas operações espaciais amigas e de capacidade para a negação da liberdade de ação aos adversários no espaço, em benefício das nossas ações de Defesa. ${ }^{26}$

Os Sistemas Espaciais que apoiam e dão suporte às ações nos demais Domínios de Combate tornam palpável o Poder Espacial. Na América do Sul, o uso de Sistemas Espaciais, com capacidades próprias, está cada

concept of operations. It's speed in terms of how we develop the leaders of the future.... Our MDC2 (MultiDomain Command \& Control) structure directing operations will be resilient and operationally agile." Apud Mccullough, Amy. Goldfein's Multi-Domain Vision. Air Force Magazine.Arlington-VA.2018. Tradução livre do autor: "As operações multidomínios têm realmente a ver com pensar sobre a maneira como penetramos, onde precisamos penetrar; como protegemos o que precisamos proteger dentro de um espaço ameaçado; como persistimos nesse ambiente pelo período de tempo em que temos que permanecer lá... Nossa nação sabe como fazer isso, mas esse músculo se atrofiou um pouco. É por isso que você ouve muitos de nós falando sobre esse atributo de velocidade. Não é apenas a velocidade na execução da guerra. É a velocidade de como estamos nos preparando para a guerra. É a velocidade na forma como adquirimos. É a velocidade de mudar nosso conceito de operações. É velocidade em termos de como desenvolvemos os líderes do futuro... As estruturas de direcionamento das operações do nosso MDC2 (Comando e Controle Multidomínio) serão resilientes e operacionalmente ágeis."

\section{Tenente Coronel da reserva da Força Aérea dos EUA (USAF).}

26 O General John "Jay" Raymond, US Space Force Commander em 2020 afirma: "U.S. Space Command will only be as good as the capabilities that the service provides... And just as U.S. Space Command has a singular focus on the war fighting aspect of space, having a Space Force with a singular focus on the space domain will be hugely, hugely helpful to us... Our desire is not to get into a conflict, we want to deter. And the way you deter is to do that from a position of strength and to say that we have the ability to protect and defend our capabilities. I think that's important work going forward." Apud Erwin, Sandra.U.S. Space Command chief Raymond: 'I'm really excited for the Space Force'.2019. Space News (https://spacenews.com/u-s-space-command-chief-raymond-im-really-excited-for-the-spaceforce/). Tradução livre do autor: "O Comando Espacial dos Estados Unidos da América será tão bom quanto as capacidades que ele proporciona, [...].E assim como o Comando Espacial dos EUA tem um foco único nos aspectos espaciais do combate, ter uma Força Espacial com um foco único no domínio espacial será imensamente, imensamente útil para nós [...] Nosso desejo não é entrar em conflito (no espaço), queremos a dissuasão. E o modo de dissuadir é fazê-lo a partir de uma posição de força e dizer a todos que temos a expertise para proteger e defender nossas capacidades." (espaciais) "Eu acho que é um trabalho importante daqui para frente." 
vez mais comum nos países vizinhos do Brasil como, por exemplo Peru, Chile e Argentina.

O início das atividades espaciais nos países ocorre, normalmente, com missões espaciais gerenciadas por organizações voltadas para a pesquisa. $\mathrm{Na}$ medida em que atingem maturidade tecnológica suficiente, passam a ser úteis para organizações operacionais, que passam a receber serviços espaciais prestados pelas organizações de pesquisa que implantaram os referidos sistemas. Com o tempo, alguns serviços espaciais passam a ser passíveis de contratação privada, outros continuam sob responsabilidade das organizações de pesquisa e, quando a natureza militar das missões passa a ser mais proeminente, passam a ser proporcionados, usualmente, por organizações militares especializadas.

De certa forma, é possível se conviver com este contexto em tempo de paz, pois as missões de suporte podem ser cumpridas de maneira razoável, devido ao fato de o país não estar sob ameaças externas. Porém, quando o uso de Sistemas Espaciais visa a se contrapor a adversários em tempo de crise, a operação deve ser resiliente, ou seja, o sistema deve possuir capacidade de operar com liberdade de ação no Domínio Espacial, mesmo sob a ameaça de ataques por adversários, o que torna essenciais as operações e as missões que garantam algum nível de controle neste Domínio de Combate.

As tarefas necessárias para se cumprir tanto as missões de suporte, quanto as de controle e defesa espacial, ficam facilitadas quando há unidade de comando operacional, garantindo maior eficiência nos serviços em tempos de crise e custos aceitáveis em tempos de paz, mesmo com múltiplas requisições de diferentes atores e parcos recursos espaciais disponíveis. ${ }^{27}$

27 O General Robert T. Herres, o primeiro Commander in Chief (CINC) do US Space Command em 1985 afirmou: "When our military forces proceed to conduct largescale operations throughout the world, it becomes necessary to uniquely control the satellites supporting those forces and scrupulously allocate this support on a case-by-case basis among the commanders in chief employing the supported forces. Up to now, we have accomplished this delicate force management by implementing special or ad hoc procedures. But as our senior leadership in the Department of Defence proceeded to establish these ad hoc arrangements for every crisis and every exercise, it became clear in a very concrete way, what men of vision had been claiming for years. It became clear that not only was the managerial wheel being reinvented at tedious intervals; but they realized that a major conflict would so increase the scope and scale of that task that an ad hoc arrangement would likely be inadequate to effectively deal with the demands placed upon it." Apud HAMBY, James R.; SMITH JR, Odell A..US Space Command - Does it Support National Military Space Requirements? Trabalho de Conclusão de Curso do Air Command and Staff College - Air University, Maxell AFB, AL, 1987. Tradução livre do autor: "Quando nossas forças militares passam a conduzir operações em larga escala em todo o mundo, torna-se necessário controlar exclusivamente os satélites que apoiam essas forças e alocar este suporte 


\title{
4. Doutrina para Domínio Espacial de Combate
}

\author{
"In short, it's the weapons systems and combat troops who will still have to \\ do the fighting, but it is the space systems which will give them the edge they \\ need to win".
}

(Brigadier General Wesley Clark, of the Air Force Space Command -1984) ${ }^{28}$

A melhor maneira de se conduzir assuntos militares, ensinada e reconhecida oficialmente em uma Força Armada, é conhecida como Doutrina de Emprego desta Força. A contínua evolução doutrinária é importante para que a Força Aérea Brasileira mantenha o foco no essencial durante as operações espaciais militares. As capacidades operacionais de cada Força Armada são derivadas, entre outros aspectos, das características intrínsecas do meio em que seus sistemas operam. $\mathrm{O}$ meio espacial possui suas características próprias e diversas do meio aéreo, que o torna um ambiente único e um recente Domínio de Combate, onde ocorrem ações isoladas ou coordenadas com ações nos demais Domínios de Combate.

A relevância que o Domínio Espacial ganhou nos teatros de operações atuais aumenta a premência de se desenvolver uma Doutrina Espacial mais abrangente, que leve em conta as capacidades dos Sistemas Espaciais e as características do Poder Espacial. A Doutrina Militar Espacial deve ser capaz de orientar as ações da Força Aérea de forma a se obter liberdade de ação no Domínio Espacial e a negar essa liberdade ao oponente.

Mais do que uma faceta, esta necessidade de liberdade de ação militar no espaço, principalmente em conflito, torna evidente a implantação de toda

escrupulosamente, caso a caso, entre os comandantes que empregam as forças apoiadas. Até agora, realizamos esse delicado gerenciamento de força implementando procedimentos especiais ou ad hoc. Mas, quando nossa liderança sênior no Departamento de Defesa estabeleceu esses arranjos ad hoc para cada crise e a todo exercício, ficou claro, de uma maneira muito concreta, o que homens de visão vinham reivindicando há anos. Ficou claro que não apenas a roda gerencial estava sendo reinventada em intervalos tediosos, mas eles perceberam que um conflito maior aumentaria tanto o escopo e a escala dessa tarefa, que um arranjo ad hoc provavelmente seria inadequado para lidar efetivamente com as demandas impostas."

28 Tradução livre do autor: "Em resumo, são os sistemas de armas e as tropas de combate que continuarão a combater, mas são os sistemas espaciais que lhes darão a vantagem que precisam para vencer”. 
uma nova classe de missões espaciais, desenhadas para se atingir o controle do espaço sempre que necessário. Quando não é possível se ter controle em nível de uma supremacia espacial, deve-se buscar um adequado nível de resiliência para a operação dos Sistemas Espaciais, que permita o emprego militar de sistemas no Domínio Espacial de forma adequada, mesmo em crises.

\section{"We have accelerated our effort to deter, defend and protect against anyo- ne who seeks to deny our ability to freely operate in space."}

(Dr Heather Wilson, Secretary of the Air Force- 2018) ${ }^{29}$

De uma maneira mais concreta, a Doutrina Militar Espacial define como os Sistemas Espaciais devem ser empregados operacionalmente para melhor explorar o Domínio Espacial em prol do Poder Militar. Neste contexto, a Doutrina precisa amparar dois grupos de missões de naturezas diferentes: Suporte Espacial, que são missões que abarcam operações de sistemas espaciais que têm como missão aumentar a eficiência e a efetividade das missões militares no mar, na terra, no ar, no espaço cibernético e no próprio espaço exterior, além das atividades espaciais que apoiam os próprios sistemas espaciais, incluindo as envolvidas em sua implantação e em sua manutenção; e Controle e Defesa Espacial que consistem em missões militares empregadas no meio espacial, ou por meio dele, que tenham potencial de garantir controle e liberdade de ação no espaço, dentro de um nível de resiliência sustentável pelo Brasil. Estas missões são levadas a cabo, isoladamente ou em conjunto com as demais Forças nos diversos Domínios. Também podem ser efetivadas por meio de coalizões espaciais. Essas missões servem como dissuasão às ações inimigas contrárias aos interesses nacionais. Um exemplo de ação de Controle e Defesa Espacial na América do Sul ocorreu, de forma indireta, na Guerra das Malvinas, quando as informações meteorológicas satelitais foram negadas aos argentinos pelos aliados dos ingleses.

As ações de Controle e Defesa Espacial são as que realmente distinguem o emprego militar do Poder Espacial da mera utilização de serviços civis. Como

29 Tradução livre do autor: "Aceleramos nossos esforços para dissuadir, nos defender e nos proteger contra qualquer um que tente negar nossa capacidade de operar livremente no espaço." 
qualquer ação militar, as ações de Controle e Defesa Espacial precisam de unidade de comando para ter emprego eficiente e efetivo, principalmente quando há múltiplos usuários, com múltiplas requisições e recursos escassos. Atualmente, o Brasil e as suas Forças Armadas já fazem uso de Sistemas Espaciais em missões cuja natureza das ações enquadram as missões no grupo das missões de Suporte Espacial. Esses Sistemas Espaciais atuais são operados por diversas organizações civis e militares, do Estado ou privadas, por meio de contratos de serviços diversos.

\section{AmeaÇas a Sistemas Espaciais}

"Our adversaries have been working to bring new weapons of war into space itself... As their actions make clear, our adversaries have transformed space into a warfighting domain already."

(Vice President of USA Mike Pence) $^{30}$

A Doutrina Militar Espacial, ao servir de base para as missões de Controle e Defesa Espacial, precisa considerar as ameaças existentes no Domínio de Combate Espacial, que são concretizadas por meio de armas contra sistemas espaciais (Antisatellite Weapons - ASAT).

Existem disponíveis, para potenciais adversários, uma grande variedade de ASAT, capazes de produzir diversos tipos de efeitos, com diferentes níveis de sofisticação tecnológica e com diversos níveis de exigência em termos de necessidades de recursos financeiros e humanos para desenvolvimento e implantação em campo.

As ASAT também diferem na maneira como são empregadas e quão difíceis elas são de serem detectadas, ou terem sua localização identificada. Os efeitos dessas armas também variam quanto à duração, podendo ser temporários ou permanentes, dependendo do tipo de sistema

30 Tradução livre do autor: "Nossos adversários têm trabalhado para levar novas armas de guerra para o espaço em si... Como suas ações deixam claro, nossos adversários já transformaram o espaço em um domínio de combate." 
empregado. ${ }^{31}$ As ASAT podem ser classificadas em quatro grandes grupos: físico cinético; físico não cinético; eletrônico; e cibernético. ${ }^{32}$ Cabe aqui comentar que, na seção 14.10.3, o Manual do Direito da Guerra dos EUA ratifica o entendimento predominante de que o Artigo IV do Tratado do Espaço proíbe apenas o uso e colocação de armas de destruição em massa em órbita e não proíbe a colocação de outros sistemas de armas no espaço. Neste ponto, o Manual cita expressamente as armas laser antissatélite e outras armas convencionais, que incluem armas defensivas suborbitais, como o sistema Terminal High Altitude Area Defense, listando estas armas como livres da proibição contida no Artigo IV. O Manual da Lei da Guerra ainda reconhece a proibição de testes atômicos no ambiente espacial como um requisito derivado do Tratado de Proibição de Testes Limitados. ${ }^{33}$

Mesmo no contexto de autodefesa, as atividades militares no espaço exterior, a partir dele ou em transição para ele, possuem aspectos ofensivos e defensivos que precisam ser considerados pelos planejadores militares ${ }^{34} \mathrm{e}$ podem ser executados ao abrigo da Carta das Nações Unidas (autodefesa) e do Tratado do Espaço (não agressão, exceto para autodefesa), além de outros

31 HARRISON, Toddet all.SPACE THREAT ASSESSMENT 2019. Center for Strategic \& International Studies.Washington, DC, 2019.

32 De uma maneira mais ampla, a caracterização da ameaça é importante para o planejamento de medidas de defesa no Domínio Espacial. Considerando os 4 grupos de ASAT acima citados, essas armas podem ser caracterizadas conforme, considerando, pelo menos, os seguintes aspectos: tipo de ataque; facilidade de identificação do agressor; reversibilidade dos danos causados; quem é capaz de perceber seus efeitos; facilidade de avaliação de danos após ataque (BDA); e danos colaterais provocados. Os planejadores das missóes de Controle e Defesa Espacial devem decidir sobre o efeito desejado ao utilizarem ASAT contra as capacidades espaciais de um adversário (EUA. Air Force Doctrine Document 2-2.1 (AFDD 2-2.1). Counterspace Operations. Washington, DC, 2004.), quais sejam: engodo; interrupção; negação; degradação; e destruição. Pode haver momentos em que operações com efeitos temporários, reversíveis no espaço sideral, são mais apropriadas que operações que degradam ou destruam permanentemente os recursos espaciais do oponente.

33 Ver Dale Stephens, The International Legal Implications of Military Space Operations: Examining the Interplay between International Humanitarian Law and the Outer Space Legal Regime, Stockton Center for the Study of International Law, 2018, Volume 94, 94 INT'L L. STUD. 75, ISSN 23752831

(https://digital-commons.usnwc.edu/cgi/viewcontent.cgi article $=1719 \&$ context=ils)

34 De acordo com o Air Force Doctrine Document 2-2.1 (AFDD 2-2.1) - Counterspace Operations de 2004, o planejamento das operações defensivas e ofensivas de Controle e Defesa Espacial devem considerar aspectos relacionados a estações terrestres; comunicações por satélite; navegação espacial; Inteligência, Vigilância e Reconhecimento (IVR); satélites meteorológicos; instalações de lançamento espacial; o uso adversário do espaço; capacidade antissatélite; e Consciência do Domínio Espacial (SDA). 
tratados que podem ser evocados em situações de conflito à luz do Direito Internacional Humanitário (DIH).

\section{O PeSE e a Quarta Geração da Força Aérea Brasileira}

"It is time for us as a service, regardless of specialty badge, to embrace space superiority with the same passion and sense of ownership as we apply to air superiority today. ... Air \& Space superiority... are not America's ordained right. We cannot take it for granted. We must plan for it, equip for it, train for it and fight for it."

(General David Goldfein, 21st Chief of Staff of the Air Force - 2018) ${ }^{35}$

O Ministério da Defesa (MD) do Brasil estabeleceu o Programa Estratégico de Sistemas Espaciais (PESE), voltado à implantação de Sistemas Espaciais que priorizam as necessidades do MD e das Forças Armadas brasileiras, disponibilizando produtos de uso predominantemente dual (civil e militar). O PESE fornece um alinhamento de alto nível entre as necessidades operacionais, as necessidades programáticas e os recursos disponíveis ou necessários para suportar o desenvolvimento do programa, de forma a atender às diretrizes da END. Considerando a PND, a END e o PESE, observa-se que já existe um arcabouço legal interno para a existência de operações espaciais que permitam ações militares envolvendo os Domínios Marítimo, Terrestre, Aéreo, Espacial e Cibernético de forma integrada, tanto para as futuras missões de Controle e Defesa Espacial, quanto para as missões de Suporte Espacial.

O início das operações espaciais a partir das novas instalações do Centro de Operações Espaciais (COPE) em Brasília e no Rio de Janeiro é um sinal do início da Quarta Geração da Força Aérea Brasileira, concretizando o interesse

35 Tradução livre do autor: "Chegou a hora de nós, como Força Armada, independentemente do crachá de especialidade, abraçarmos a superioridade espacial com a mesma paixão e senso de propriedade que dedicamos hoje à superioridade aérea... Superioridade aérea e espacial... não é um direito ordenado à América. Não podemos dar isso como certo. Precisamos planejar, equipar e treinar e lutar por isso." 
cada vez maior do Comando da Aeronáutica no uso operacional do espaço exterior, dispondo de tecnologias de vanguarda e fundamentos cada vez mais avançados em suas atividades no cumprimento de sua missão constitucional.

O COPE constitui uma oportunidade para aproveitar as facilidades oferecidas nas novas edificações para aumentar a efetividade e a eficiência das ações conjuntas das Forças Armadas brasileiras em combates nos múltiplos domínios, quais sejam, o marítimo, terrestre, aéreo, espacial e cibernético. Nesta nova fase da Força Aérea, busca-se evoluir, passando das operações voltadas para aplicações de ciência, tecnologia e inovação e dos serviços prestados em instalações que hoje operam em ambiente sem adversários, para operações mais dinâmicas e focadas nos efeitos desejados em ações militares, com o uso integrado do poder espacial para a defesa do Brasil, conjugando judiciosamente os meios militares, civis e até privados, disponíveis para operação mesmo em tempos de conflitos e sob ameaça de oponentes racionais.

\section{Consideraçôes Finais}

“A primeira geração da Força Aérea Brasileira foi o início da operação dos avióes. A segunda geração foi marcada pelo desenvolvimento das rotas aéreas, dos aeroportos em todo pais e da criação da indústria aeronáutica no Brasil. A terceira geração foi a consolidação do Poder Aéreo, com vetores de última geração e armamentos modernos equipando as unidades da FAB, além da grande evolução doutrinária no emprego deste Poder. Agora, o Espaço é a quarta geração da Força Aérea Brasileira!"

(Ten Brig Ar Antônio Carlos Moretti Bermudez - Comandante da Aeronáutica - 2019)

A evolução tecnológica traz em si mesma a semente para transformações de comportamentos sociais e de pensamento. Estas transformações são ainda mais inquietantes quando têm como palco a aplicação da norma jurídica internacional em conflitos que envolvem o emprego militar no Domínio espacial, ou atividades militares em outros Domínios de combate que 
envolvam o espaço exterior de alguma maneira. Este fato inexorável trazido à baila pela facilidade de acesso e uso do espaço exterior, graças à tecnologia disponível, causa uma pressão factual que precisa ser entendida em seus aspectos jurídicos, preferencialmente, antes do uso dos novos conceitos em um conflito real.

Para colaborar com o entendimento desta questão, este artigo apresentou o caso brasileiro, onde a Força Aérea Brasileira traduziu o entendimento do Brasil quanto ao Tradado do Espaço e à Carta das Nações Unidas, estruturando sua aplicação militar do espaço exterior de acordo com os documentos políticos e doutrinários do Ministério da Defesa do Brasil, sabidamente, a Política de Defesa Nacional, a Estratégia Nacional de Defesa e o Programa Estratégico de Sistemas Espaciais.

Esta prática brasileira está alinhada a outras nações e a acadêmicos, que lidam com o Tratado do Espaço em tempos de paz ou de guerra, interpretando de maneira mais profunda o termo "propósitos pacíficos", contido no referido Tratado no seu Artigo IV e no preambulo, ao equipará-lo ao termo "não agressivo." Isso também mantem a presença militar no espaço exterior consistente com a Carta das Nações Unidas e outras normas internacionais, que admitem o direito de autodefesa do Estado, que é garantido coma presença militar. $\mathrm{O}$ artigo em pauta não se conteve em apenas citar a prática brasileira, mas também apresentou propostas doutrinárias para a Força Aérea Brasileira que corroboram com esta interpretação do Tratado do Espaço ao tratar das aplicações espaciais militares, seja na paz ou em conflitos.

À luz da Convenção de Viena sobre o Direito dos Tratados, ${ }^{36}$ a prática do Estado, subsequente à adesão a um Tratado, é, inter alia, elemento essencial para interpretar as disposições do tratado, conforme afirmado em seu Artigo 31: “[o] tratado deve ser interpretado de boa-fé, de acordo com o significado comum a ser dado aos termos do tratado em seu contexto e à luz de seu objeto e propósito... Deve ser levado em consideração, juntamente com o contexto: Qualquer prática subsequente na aplicação do tratado que estabeleça o acordo das partes quanto à sua interpretação.”

Cabe lembrar que não há notícia, até o momento, de condução de conflitos armados no espaço exterior, o que não permite a verificação de prática estatal

36 Vienna Convention on the Law of Treaties, May 23, 1969, 1155 U.N.T.S. 331. 
subsequente à adesão ao Tratado do Espaço, que seja de domínio público, e a que se possa basear para interpretar o significado de disposições do Tratado fora da situação de paz. Mesmo neste contexto, ainda é possível verificar que a Comissão de Direito Internacional, em seus últimos relatórios, reafirma que a prática do Estado é um autêntico meio de interpretação, relacionada ao tratado em pauta, e tem sido identificada como ação legislativa, prática administrativa e atos oficiais, bem como ação, reação, aquiescência e silêncio relevante por outros Estados a esses atos. ${ }^{37}$

No momento, ainda não existe norma supra - nacional que permitiria exegese autêntica para reconciliar os diferentes regimes que tratam do uso militar no espaço exterior, principalmente em tempos de conflito. Onde houver incidência de mecanismos jurídicos antinômicos em relação à mesma situação fática, o Direito dos Tratados irá nortear a solução. Entretanto, ressaltar, os termos "legal e ilegal" não são sinônimos de "certo e errado." No cenário espacial, o dilema de fazer o que é "legal" versus o que é "certo" vem assumindo proporções complexas de confrontos e divergências de interpretação entre os Estados, ${ }^{38}$ mormente considerando-se que as fontes clássicas

37 A Comissão de Direito Internacional (CDI) das Nações Unidas, apresentou em seu Report of the International Law Commission (ILC), Seventieth session, (30 April-1 June and 2 July-10 August 2018), no Chapter IV Subsequent agreements and subsequent practice in relation to the interpretation of treaties, seção E: Text of the draft conclusions on subsequent agreements and subsequent practice in relation to the interpretation of treaties, Part Two, Conclusion 3 Subsequent agreements and subsequent practice as authentic means of interpretation, a seguinte afirmação: "Subsequent agreements and subsequent practice under article 31, paragraph 3 (a) and (b), being objective evidence of the understanding of the parties as to the meaning of the treaty, are authentic means of interpretation, in the application of the general rule of treaty interpretation reflected in article 31.Chapter IV Subsequent agreements and subsequent practice in relation to the interpretation of treaties". General Assembly. Official Records. Seventy-third Session. Supplement No. 10 (A/73/10). United Nations - New York, 2018. Acessível no sítio: http:// www.qil-qdi.org/international-law-commission-and-role-of-subsequent-practice-as-a-meansof-interpretation-under-articles-31-and-32-vclt/http://www.qil-qdi.org/international-lawcommission-and-role-of-subsequent-practice-as-a-means-of-interpretation-under-articles-31and-32-vclt/ .

Tradução livre do autor: Os acordos subsequentes e a prática subsequente nos termos do artigo 31, parágrafo 3 (a) e (b), sendo evidência objetiva do entendimento das partes quanto ao significado do tratado, são meios autênticos de interpretação, na aplicação da regra geral de interpretação do tratado refletida no artigo 31. Capítulo IV Acordos subsequentes e prática subsequente em relação à interpretação dos tratados.

38 Mirmina observa "In fact, Space Law has very few explicit legal probibitions. The Outer Space Treaty (OST) contains a few restrictions (e.g. no installation of nuclear weapons in space, no testing of military weapons on celestial bodies, no harmful contamination of other celestial bodies, no national appropriation of outer space) but, overall, it is permissive. It guarantees that space shall be free for exploration and use, and that activities in space shall be conducted in accordance with international law [...] While perhaps not breaking any explicit laws per se, activities as far ranging as intentionally destroying satellites in outer 
do Direito Espacial merecem revisão para a elaboração de normas jurídicas internacionais com elevado grau de efetividade e que cristalizem uma Ética para os usos do espalho exterior.

Em conclusão, em tempos de paz, o Tratado de Espaço pode ser considerado lex specialis para a presença militar no espaço exterior. Porém, em tempos de conflito a reflexão é sobre a convergência destes regimes jurídicos internacionais a tutelarem as situações fáticas bélicas emergentes no espaço exterior ou a partir dele, e, sobre possíveis antinomias que irão surgir. Este fonômeno justifica a relevância do estudo sobre as fontes do Direito Internacional que, em constante fluxo e refluxo, geram complexo ordenamento jurídico decorrente da íntima vinculação entre regras consuetudinárias, normas expressas em tratados e o peso irrefutável dos códigos de conduta e das legislações nacionais sobre a temática.

Mais uma vez, o caso brasileiro vem à tona neste artigo para colaborar com uma visão particular do Brasil quanto ao emprego de sistemas militares no espaço sideral, em benefício de aplicações civis e militares, utilizando a tecnologia espacial como ferramenta essencial de autodefesa. Esses momentos poderão expor um choque de Ethos $^{39}$ e compromisso profissional o que aumenta a necessidade da busca de regime jurídico que possa ser o pilar do complexo equilíbrio que se pretende dos Estados na interpretação e operacionalização do corpus juris a ser aplicado em possíveis situações de emprego militar em conflitos no espaço.

A "Ethos" subjacente à norma jurídica reflete as características da cultura legal de determinada sociedade. $\mathrm{Na}$ realidade, na formação de normas jurídicas interferem os princípios básicos da Sociedade cujas aspirações se desejam reger. ${ }^{40} \mathrm{E}$ assim o é para o Direito Internacional Espacial, eivado de especificidades, consequência das características históricas, geográficas, político-econômicas e militares que norteiam a utilização do espaço exterior.

space, launching roadsters....can all do damage the space environment. Moreover, they do nothing to foster confidence or exhibit transparency in outer space." Steven Mirmina, The Times is Always Right to do What is Right, in Georgetown Journal of International Law, Vol.51, 2020, 1-2.

39 "The ethos of one specialized law is not necessarily identical to that of a neighboring specialization and the two may not be easily reconciled." Dale Stephens, supra nota 3, 84 .

40 Maria Helena Fonseca de Souza Rolim, A Tutela Jurídica dos Recursos Vivos do Mar na Zona Econômica Exclusiva, Max Limonad, SP, 1988, 35. 
Entretanto, a participação no cenário jurídico internacional de Estados formalmente iguais, mas com desigualdades reais, suscita confrontos e paradoxos inevitavelmente cristalizados nos Tratados e Códigos de Condutas que tutelam a temática. Certamente, a interpretação de tratado à luz de qualquer prática do Estado posterior ao tratado deverá levar também em consideração os meios suplementares de interpretação, em particular os trabalhos preparatórios do tratado e às circunstâncias de sua conclusão.

A análise pragmática e teórico prospectiva dos avanços da tecnologia militar, bem como os usos militares no espaço exterior, com ênfase para Defesa, levou a Força Aérea Brasileira a estruturar sua visão particular quanto ao entendimento do Brasil sobre o Tradado do Espaço e à Carta das Nações Unidas. Esta senda vem trazendo o desenvolvendo e o amadurecimento de sua doutrina de emprego dos sistemas de Defesa no espaço exterior, em benefício de aplicações civis e militares. A utilização da tecnologia espacial, como ferramenta essencial de autodefesa, é uma situação fática que serve de palco para a atualização de instrumentos jurídicos que deem a necessária guarida para operações militares no Domínio Espacial, seja em tempos de paz ou durante conflitos. 